\title{
INCREASE PRODUCTION OF SPRUCE BY GIRDLING HARDWOODS
}

\author{
B. M. Westrelde, Senior Silviculturist \\ U.S. Department of Agriculture \\ Northeastern Forest Experiment Station ${ }^{i}$
}

1

UMEROUS experiments demonstrate that girdling hardwoods to release spruce is a most effective measure for increasing the production of spruce. This conclusion was further substantiated by remeasurement in 1935 of the Corbin Park girdling plots. The 3 half-acre plots comprising this experiment are located at Corbin Park, near Newport, ${ }^{1}$ In cerreration with Yale University, New Haven, Comecticut.

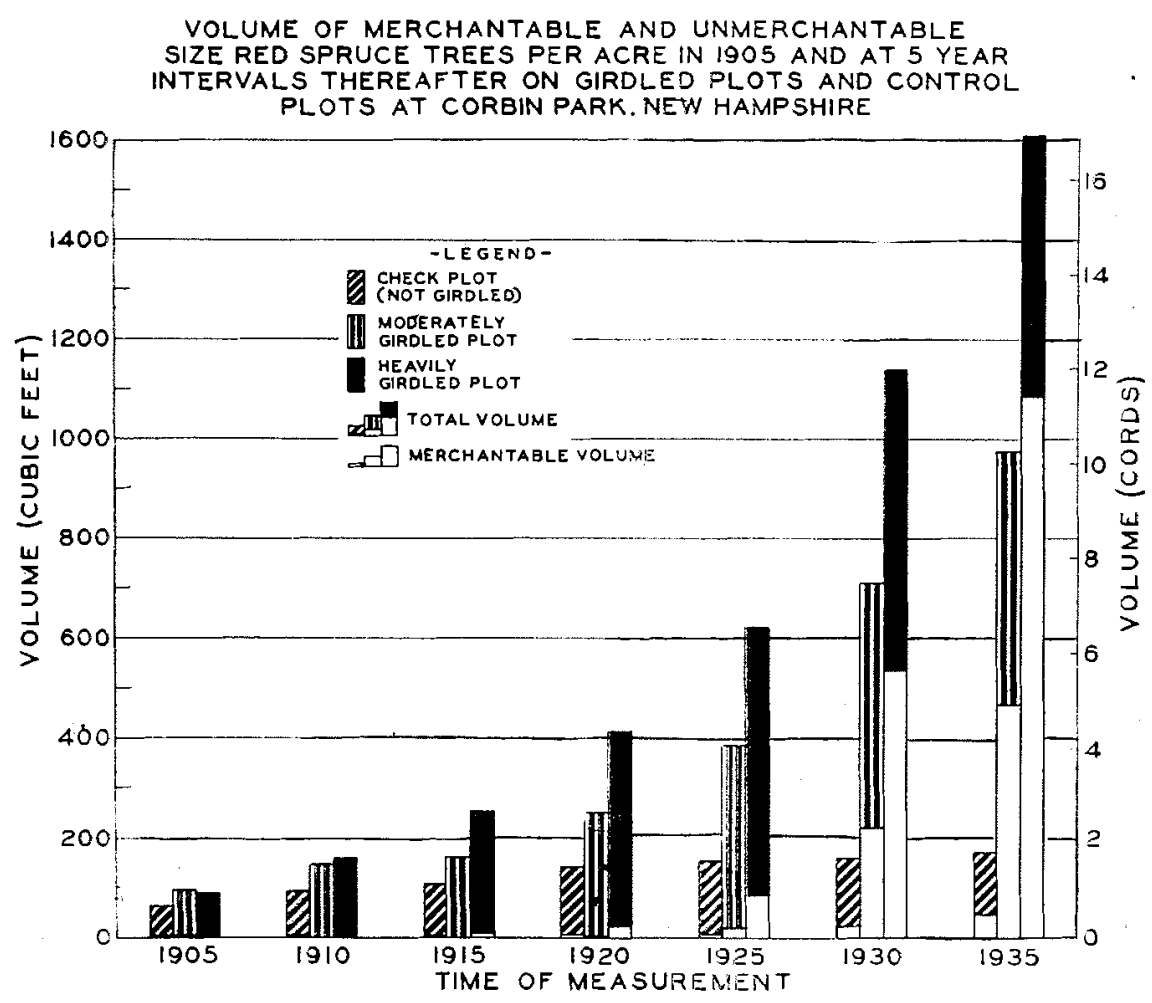


New Hampshire. The study was initiated by the U.S. Forest Service in 1905 to determine the effect of varying degrees of hardwood girdling in a 60 year old northern hardwood stand containing a dense understory of spruce and sapling reproduction. In two successive cutting and girdling operations, practically all the hardwoods were girdled on one plot, approximately 65 percent on a second, while the third was held intact as a control. Since the preliminary report on this experiment, showing the status in $1927^{2}$, the plots have been measured twice, once in 1930, and again in 1935. Growth on the girdled plots has been so rapid during the past 10 years that a second progress report appears justified at this time.

The stimulating effect of girdling is brought out by a comparison of spruce volumes on the plots at various measurement periods. Measurements at 5 year intervals following the initial girdling showed pulpwood species to be growing much more rapidly on the girdled plots than on the untreated plot. Moreover, the response to girdling was more striking on the heavily girdled than the moderately girded plot. These facts are clearly brought out in the accompanying chart. The heavily girdled plot, which has an initial spruce volume less than the moderately girdled plot, 5 years following treatment had a greater volume than the moderately girdled plot. In 1935 the stand of spruce on the heavily girdled plot amounted to 1607 cubic feet per acre and that on the moderately girdled plot 974 cuhic fect per acre in contrast with 172 cubic feet per acre on the untruated piot. Expressed on an annual growth basis, this amounts to an average of 50,29 , and 3 cubic feet respectively for the 30 year period. Rate of growth on the girdled plots showed decided gains during the later stages of the experiment. During the past 10 years the heavily girdled plot has heen growing at the rate of 98 cubic feet per acre per year, the moderately girdled, 58 cubic feet, and the ungirdled plo* less than 2 cubic feet. Of considerable interest and importance, particularly to a pulpwood operator, is the actual quantity of spruce of merchantable or pulpwood size available at a particular period. This information is also shown on the chart. Total volume is represented by the full length of the bar; merchantable volume by the white portion only. It will be noted that for the first 20 years following treatment, practically all of the materiol was of non-merchantable size. 'Thereafter, however, the percentage of merchantable material on the girdled plots rose rapidly. In 1930, 30 percent of the volume on the moderately girdled plot and 47 percent on the heavily girdled plot was of merchantable size. Five years later nearly half the volume on the noderately girdled plot and two-thirds the volume on the heavily girdled plot was of pulpwood size. This is equivalent to 4.9 cords and 11.4 cords per acre respectively. Thus, a thinning of sufficient volume to liquidate the girdling investment could be made now, leaving the grow-

2 Technical Note No. 1, Northeastern Forest Experinent Station, 1929. 
ing stock in excellent condition for continued rapid development which would assure additional returns at an early date.

A forecast of probable future pulpwood yield leads to some interesting corollaries. Ten years hence, when it is estimated the bulk of the spruce will have reached merchantable size, the net gain in softwood pulpwood attributable solely to girdling will amount to 20 cords worth $\$ 50.00$ on the heavily girdled plot, and 11 cords worth $\$ 27.50$ on the moderately girdled plot. The cost of the heavy and moderate girdling is estimated at $\$ 2.60$ and $\$ 2.00$ per acre respectively.

The following conclusions may be drawn from this experiment:

1. Red spruce stands liberated by girdling produce conifer pulpwood several times as rapidly as comparable stands not liberated.

2. Wherever a satisfactory softwood understory is present, girdling of hardwoods will convert a mixed spruce hardwood stand into a stand entirely of conifers.

3. Even in cases in which the conifer pulpwood crop cannot be harvested until 40 or 50 years after girdling, satisfactory returns may be realized on the investment in girdling. 